\title{
Discours
}

Revue de linguistique, psycholinguistique et

informatique. A journal of linguistics, psycholinguistics and computational linguistics

$10 \mid 2012$

Multidisciplinary Perspectives on Signalling Text Organisation

\section{Understanding How Headings Influence Text Processing}

Julie Lemarié, Robert F. Lorch Jr. and Marie-Paule Péry-Woodley

\section{OpenEdition}

\section{Journals}

Electronic version

URL: http://journals.openedition.org/discours/8600

DOI: $10.4000 /$ discours. 8600

ISSN: 1963-1723

\section{Publisher:}

Laboratoire LATTICE, Presses universitaires de Caen

\section{Electronic reference}

Julie Lemarié, Robert F. Lorch Jr. and Marie-Paule Péry-Woodley, « Understanding How Headings Influence Text Processing », Discours [Online], 10 | 2012, Online since 16 July 2012, connection on 30 April 2019. URL : http://journals.openedition.org/discours/8600 ; DOI : 10.4000/discours.8600 

Revue de linguistique, psycholinguistique et informatique

\title{
Understanding How \\ Headings Influence Text Processing
}

\author{
Julie Lemarié \\ CLLE-LTC \\ CNRS \& Université de Toulouse (UTM)
}

Robert F. Lorch, Jr.

CLLE

CNRS \& Université de Toulouse (UTM)

Department of Psychology

University of Kentucky

Marie-Paule Péry-Woodley

CLLE-ERSS

CNRS \& Université de Toulouse (UTM) 



\title{
Understanding How \\ Headings Influence Text Processing
}

\author{
Julie Lemarié \\ CLLE-LTC \\ CNRS \& Université de Toulouse (UTM) \\ Robert F. Lorch, Jr. \\ CLLE \\ CNRS \& Université de Toulouse (UTM) \\ Department of Psychology \\ University of Kentucky \\ Marie-Paule Péry-Woodley \\ CLLE-ERSS \\ CNRS \& Université de Toulouse (UTM)
}

Titles and headings are commonly used signaling devices in expository texts. Researchers in cognitive and educational psychology have demonstrated several important effects of headings and titles on text processing: headings improve memory for text organization; headings influence text comprehension by activating readers' prior knowledge; and titles can bias text comprehension by their emphasis on a particular text topic. However, the lack of precise linguistic analyses of titles/headings has limited both the scope of empirical research and the precision of conclusions. We present a theory of signaling devices that provides a detailed analysis of variation in titles and headings and generates predictions concerning their effects. We discuss the implications of our analyses for research on titles and headings and summarize recent research findings that illustrate the validity of a central component of our analyses. Finally, we propose some future research directions integrating insights from linguistics for the study of how headings and titles affect text processing.

Keywords: text signals, comprehension, headings, text cognitive processing

Les titres et intertitres sont des dispositifs de signalisation fréquemment utilisés dans les textes expositifs. De nombreuses recherches réalisées en psychologie cognitive et psychologie des apprentissages ont mis en évidence leurs effets sur le traitement du texte par le lecteur: les intertitres améliorent la représentation mnésique de l'organisation du texte et influencent la compréhension du texte par un mécanisme d'activation des connaissances antérieures du lecteur. Les titres généraux, lorsqu'ils mettent en avant un des thèmes du texte, biaisent la compréhension du texte. Cependant, l'absence d'analyse linguistique approfondie des titres et intertitres a limité la portée de ces travaux et a mené à des conclusions méritant d'être affinées. Nous présentons une théorie générale de la signalisation des textes qui propose un cadre d'analyse détaillé de la variabilité des titres et intertitres et génère des prédictions quant à leurs effets. Nous discutons les implications de ce cadre pour la recherche sur les titres et intertitres. Nous résumons des résultats récents qui illustrent la validité d'une composante centrale de nos analyses. Enfin, nous proposons 
des perspectives de recherche intégrant des résultats de travaux en linguistique pour l'étude des effets des titres et intertitres sur le traitement cognitif du texte.

Mots clés: signaux textuels, compréhension, titres, traitement cognitif du texte

Headings are ubiquitous in expository texts and for good reason. An expository text of any length typically has a complex structure that poses substantial challenges to readers. In France, for instance, it has been observed by La Haye et al. (2009) that I0\% of young adults do not have the strategic skills to effectively process complex documents (i.e. documents with signaled text, pictures, graphs, tables). Recognizing the demands of complex exposition, authors will often use a variety of writing devices to signal text organization and important content. The inclusion of headings, for instance, can support readers by identifying major topics and ideas, by emphasizing the structure of the text, and by serving as labels that can support access to sections within the text (Waller, 1987). In fact, there is a relatively extensive empirical literature in psychology that generally supports the hypothesis that signals may help processing of expository text (Lorch, 1989). In this paper, we briefly review the relevant findings, then we provide a critique of the research literature, arguing that our understanding of how headings influence text processing would benefit from a linguistically-based analysis of headings. We briefly present a general theory of signaling devices that provides such an analysis and we summarize some recent cognitive research demonstrating the validity and utility of the analysis. Finally, we address the question of what future research directions are suggested by our framework.

\section{A brief review of the cognitive literature on headings}

There is a long history of research in psychology addressing the question of how headings influence various aspects of text processing (Bransford \& Johnson, 1972; Schallert, 1976). Two lines of research on the topic can be identified. Within educational psychology, researchers have been primarily interested in the possibility that well-constructed headings might facilitate learning from text (Brooks et al., I983; Hartley \& Trueman, 1983; Holley et al., 198I; Krug et al., 1989). If principles of heading construction and placement can be identified that consistently improve learning from textbooks then authors can write more effectively to the benefit of student learning. Within cognitive psychology, headings have been used as a means to manipulate context in order to investigate effects of global context on comprehension and memory processes. In contrast to educational psychology's emphasis on identifying the learning benefits associated with the use of headings, cognitive psychologists have focused on the processes by which headings influence text processing.

Much research has investigated how the presence of headings in a text influences subsequent memory for the text. In a prototypical experiment, participants read a text with headings or the same text without headings then receive a test of 
their memory for content. When memory is tested by assessing readers' abilities to recognize specific content from a text, headings are typically not found to influence performance (Spyridakis, 1989; Spyridakis \& Standal, 1986 and 1987). However, this null result is not surprising because headings conventionally communicate information about text organization and recognition memory tests are often insensitive to organizational factors. The picture is different when memory is assessed by simply asking readers to recall all that they can remember from the text. Although headings do not always lead to improved free recall (Lorch \& Lorch, 1996b), several studies have found that recall of text is better if the text contains headings than if the text does not contain headings (Holley et al., 1981; Krug et al., 1989; Lorch \& Lorch, 1996a; Sanchez, Lorch \& Lorch, 200I). The presence of headings also aids summarization (Brooks et al., 1983; Holley et al., ı98г; Hyönä \& Lorch, 2004; Krug et al., 1989; Lorch \& Lorch, 1996a; Lorch et al., 200I; Sanchez, Lorch \& Lorch, 200I) and outlining from memory (Brooks et al., 1983). When the research on headings is combined with similar research on the effects of other structure-emphasizing signaling devices (e.g. advance outlines), a relatively consistent picture emerges. First, headings attract the attention of readers as they read, causing them to alter their processing strategies so as to focus more on the text's topics (Cauchard et al., 2oroa, 2orob; Hyönä \& Lorch, 2004). The additional processing of the headings results in a more systematic and complete representation of the topic structure of the text than would occur for the same text without headings (Lorch \& Lorch, 1996b). At recall, the topic structure representation is available to guide the retrieval of topics and their associated content, resulting in more complete recall of the text content (Lorch \& Lorch, 1985; Lorch \& Lorch, I996b; Lorch, Lorch \& Inman, 1993; Mayer, Dyck \& Cook, 1984; Meyer et al., 1998; Sanchez, Lorch \& Lorch, 200I).

The research summarized in the preceding paragraph sought to determine whether and how headings aid memory for text. A second set of investigations used free recall to understand how headings might influence readers' understanding of text (Bock, I980; Kozminsky, 1977; Schallert, 1976; Schwarz \& Flammer, 198I). The general strategy followed in this research was to construct texts with competing themes and manipulate the title of the text to emphasize one of the two themes, then observe the effects on free recall. The finding from this research is that readers build a representation of the text that is organized around the biasing title (Bock, 1980; Kozminsky, 1977; Schwarz \& Flammer, 198I) with the consequence that memory is better for content that is more closely associated with the theme emphasized by the biasing title than for content associated with the alternative theme. Similarly, Eyrolle, Virbel and Lemarié (2008) showed that users confronted with work documents containing titles that only partially reflect the text content fail to identify topics that are not represented in the title. In sum, these results are consistent with those reviewed above in demonstrating an effect of titles on readers' representations of text structure. In addition, they demonstrate that titles can alter readers' understanding of the content by emphasizing some content over other content. 
Finally, several researchers have asked how titles and headings might influence the interpretation of text content. The general strategy in this research has been to construct texts containing vague referents then manipulate the title to alter the context for interpreting the referents. In one series of experiments, Dooling and his colleagues (Dooling \& Lachman, 197I; Dooling \& Mullet, 1973; Sulin \& Dooling, 1974) demonstrated that readers could be induced to "remember" content that was not actually presented when the title indicated that the text was about a topic for which the readers had relevant background knowledge. Related to Dooling's work is the finding that if readers are provided with a disambiguating title for a text containing ambiguous referents, they are better able to recall text content and they report better comprehension of the texts (Bransford \& Johnson, 1972). Subsequent researchers examined the influence of such disambiguating titles on the online processing of the texts (Smith \& Swinney, 1992; Wiley \& Rayner, 200o). This research shows that a title influences attention to ambiguous words that are specifically related to the title. In sum, titles have been shown to influence the interpretation of specific text content by activating readers' prior knowledge about the topic of the text.

To summarize our review, psychological research on headings has established that headings influence memory and comprehension of text. Their influence is achieved via at least three mechanisms. First, when headings are used to highlight the organization of topics in a well-structured text, they lead to better memory for that organization; in turn, better memory for text organization leads to better overall recall. Second, titles emphasize specific topics or themes, which biases readers' understanding of the text in the direction of the emphasized topics and themes. Finally, by establishing a context, headings can influence the interpretation of text content by causing readers to use relevant background knowledge to guide comprehension. Thus, the psychological literature presents an informative, coherent body of results on the effects of titles and headings.

\section{Shortcomings of previous research}

Despite the useful findings of prior psychological research, there are several shortcomings of the research literature that originate in an inadequate analysis of headings as an object of study. These shortcomings limit the theoretical and practical impact of the research. The most basic limitation is the lack of any attempt to provide a formal and precise definition of titles/headings. In fact, it is common for investigators not to provide a description of how they constructed the titles/ headings for their research. There are even examples of studies that do not provide examples of the headings they actually used (e.g. Brooks et al., 1983; Mayer, 1978). Perhaps the closest approximation to a definition of headings in the literature is the statement that "titles and headings label the dominant topic or theme of the subsequent text" (Lorch, 1989: 210). This statement is a rough definition of headings that corresponds well to the implicit definition that most researchers 
appear to use, but it is demonstrably inadequate as a general definition of titles and headings. For example, it is common to encounter headings such as "Introduction" or "Conclusion". These examples do not state the topic or theme of a section of text; rather, they provide information about the function of a section of text.

As could be expected given Lorch's (1989) overly-restrictive definition, the scope of research on headings has been limited. Most researchers have studied titles/ headings that communicate information about the text topic. For instance, titles like "Hydrochloric Acid instead of Grape Juice! A Gruesome Accident in Munich" (Bock, 1980) or "Christopher Columbus Discovering America" and headings like "Random Cell Damage as a Cause of Ageing” (Surber \& Schroeder, 2007) all provide information about the topic. Yet, research in linguistics using a corpus-based approach has shown that authors use a great variety of headings that may be analyzed along several dimensions (Ho-Dac, Jacques \& Rebeyrolle, 2004; Jacques, 2005; Jacques \& Rebeyrolle, 2006; Rebeyrolle, Jacques \& Péry-Woodley, 2009). Ho-Dac, Jacques and Rebeyrolle (2004) approach this plurality of functional dimensions in texts by referring to the three metafunctions which, in systemic functional linguistics, organize language resources (Halliday, I985): (I) the interpersonal metafunction is concerned with the way language encodes interaction; (2) the ideational metafunction refers to language resources used to represent experience; and (3) the textual metafunction refers to language resources concerned with the construction of text. As applied to titles and headings, ( $\mathrm{I}$ ) the interpersonal metafunction is particularly apparent in titles and headings which are formulated to capture the reader's interest, for example when titles are puns; (2) the ideational metafunction is obvious in titles containing expressions referring to world objects; and (3) the textual metafunction, which is concerned not with outside referents or participants but with the creation of text as text, is present in all titles and headings since they visibly segment and organize text. Many titles and headings seem to work mostly within this third component: for example "Chapter I", "Introduction", or even "Literature Review" in a genre where such a section is totally expected. From this perspective, psychological researchers appear to have taken a simplistic view of titles and headings, ignoring their capacity to fulfil and possibly combine several functions. The empirical literature should therefore be critically revisited, as it may overgeneralize findings which apply only to certain types of headings. In section 5, we suggest some directions for future research on the functional diversity of titles/headings, their relation to the text they head, and their interrelations.

Related to the lack of definition of headings, previous investigators have failed to show an appreciation of the systematic ways in which headings can vary. Even within the category of topic-identifying headings, it is possible to identify several dimensions of variation in headings. One potentially important dimension concerns the visual properties of headings; headings vary in their typographical and spatial properties. Many studies fail to provide information about the visual properties of their stimuli. This is unfortunate because it is likely that the titles and headings used in different experiments vary on this dimension in ways that might influence processing. Visual 
contrast provided by typographical variation and spacing manipulations have been demonstrated to influence online processing of text (Lorch, Lorch \& Klusewitz, 1995) and memory for the signaled content (Fowler \& Barker, 1974; Lorch, Lorch \& Klusewitz, 1995). Therefore, variation in the visual properties of titles and headings may be associated with variation in their effects on text processing.

A second dimension of variation might be termed the informativeness of the heading, or its degree of elaboration. Some headings provide only the major referent for a section of text. For example, the single word heading "Pandas" implies that the subsequent text section will provide information about panda bears, but does not imply anything more specific. The heading provides a context for integrating subsequent information, but leaves it to the reader to identify or construct the main points of the section. In contrast, a heading like "Air Flow: Air Moves Faster across Top of Wing" (Mautone \& Mayer, 20oI) is much more specific in its implications, communicating what is presumably the major conclusion of the subsequent text section. Assuming that the heading is, in fact, an accurate statement of the main point of the section, the reader is relieved of the ambiguity and work of identifying or constructing this conclusion.

A third dimension of variation in headings concerns the relationship between a heading and the content of the section that it heads. Again, previous investigations generally fail to provide information about this potentially important source of variation in their text construction. Let us contrast two situations. In one (e.g. Lorch \& Lorch, 1995; Sanchez, Lorch \& Lorch, 200I), the information contained in a heading may be literally repeated in the topic-introducing sentence that begins the text section. For example, the heading "Alternative Energy Sources" immediately precedes a section that begins with the sentence "Several alternative energy sources are available". The control version of the text omits the headings but retains the topic sentences and therefore retains the same information content as the experimental version of the text. The function of the headings is to foreground specific content that is also available in the text. Under these conditions, headings result in less attention to the topic sentences of the text but memory for text content is facilitated by the presence of headings (Hyönä \& Lorch, 2004; Lorch, Lorch \& Inman, 1993).

In the contrasting situation, it is common for authors not to repeat the content of a heading in the content of the section that it heads. It is likely that text processing is different under these circumstances than under conditions where headings are redundant with specific text content. A comparison of a text with vs. without headings under these conditions means that the two texts being compared differ to some extent in the information they communicate. The nature and extent of the effect on processing of manipulating headings in this way almost surely depends on exactly what information is lost when the headings are omitted. In fact, the existing literature has investigated some extreme examples where the ability to resolve referents in a text is heavily dependent on presentation of a context-establishing 
heading and the effects on memory for text content are striking (Bransford \& Johnson, 1972; Dooling \& Lachman, 1971).

As we begin to realize that there are important dimensions of variation in headings that have not been taken into account in prior investigations, we also realize that the conclusions from previous research are coarse-grained. Not only is it the case that conclusions are restricted to topic-identifying headings, but there has also not been any careful examination of how their visual realization, informativeness, and relationship to text content may influence text processing. To take one simple example, consider an experiment in which memory for a text is compared for a version of the text that contains topic-identifying headings and a control version of the text that omits the headings and the white space inserted to set off the headings from the body of the text. Are differences in performance on the two text versions attributable to the fact that the control text omitted topic-identifying headings? Or are performance differences due to the loss of segmentation cues provided (in part) by the white space? Or both?

Beyond the theoretical limitations, the failure to adequately analyze the range and variation in headings limits the potential applications of research findings. For example, an educator interested in text design might want to make recommendations about how to construct headings to facilitate learning from text. Some relevant questions are: What types of information should be included in the headings (e.g. topic-identifying, organization-identifying, function-identifying)? How should the headings relate to the content they signal? What should the visual properties of the headings be? In short, the types of variation we have noted are very relevant to text design, but we have not yet designed research to answer these questions. To pursue such questions, we require a broader conception of headings and a systematic analysis of variation in headings. In the next section, we summarize a general theory of text signals that addresses these goals.

\section{SARA: a theory of text signals}

SARA is an acronym for the conditions under which signals are hypothesized to affect text processing (Lemarié et al., 2008). It stands for "Signaling Available, Relevant, Accessible" information. SARA is a theory intended both as an analysis of signaling devices and as a framework for understanding how signaling devices influence text processing. As one important type of signaling device, headings are addressed within the SARA framework. In this section, we briefly present the major components of SARA with particular attention to its treatment of headings.

SARA has two main components: a text-based and a reader-based analysis of signaling devices. The text-based analysis of signals defines signaling and provides a structured approach to characterizing a signaling device along several dimensions. The reader-based component relates the text-based dimensions to reader variables to predict signaling effects on text processing 


\subsection{The text-based component of SARA}

This component of the theory is adapted from the logico-linguistic Textual Architecture Model [TAM] (Pascual, I991; Virbel, 1985 and 1989). The goal of TAM is to supply a semantic analysis and a logical model of text formatting properties. It approaches this task by building on the notion of metalanguage (Harris, I968 and I99I) and key concepts taken from Speech Act Theory (Austin, 1972; Grice, I957; Searle, 1969 and 1979). One central claim in TAM is that text formatting properties are meaningful because they are reduced forms of metasentences. In contrast to text sentences that refer to the world, metasentences refer to the text itself. As an example, the sentence "I divide this article into four parts" is a metasentence because it conveys information about the text rather than about objects or events in the world. A second critical claim in TAM is that metasentences express an author's intention to perform a textual act whose illocutionary force is directed toward the text itself. A textual act refers to actions concerning the text and its organization. "To entitle", "to divide into chapters", "to insist" all express textual acts. An important implication of these claims is that for any signaling device, one may re-construct its underlying metasentence and extract useful information from it. Thus, TAM provides a foundation for both a definition of signals and an analysis of their key properties.

Based on TAM's analyses, SARA defines a signal as "the realization in a printed text of a metasentence, or set of metasentences" (Lemarié et al., 2008: 3I). Within this framework, headings and titles may be defined as text objects that are typographically and spatially distinguished from the rest of the text and whose minimal function is to label another text object. The metasentence corresponding to a heading like "Oil Spills" would have the form "I title/label this text unit 'Oil Spills". In the case of titles, the labeled text object is an entire text; in the case of headings, the labeled text object is a text part (e.g. a chapter, a section, etc.). This definition is consistent with those of Virbel (2005) and Genette (1987). According to Genette (I987), titles may have four different functions: (I) to identify or label a book; (2) to provide information about the text topic; (3) to indicate the nature of the book; and (4) to attract the interest of readers. However, as in our definition, the only mandatory function that a title must fulfil is the labeling function. Other researchers (Eyrolle, Virbel \& Lemarié, 2008; Virbel, 2002) make additional distinctions between thematic, functional, relational, framing and performative titles.

Both Genette (1987) and Virbel (2008) further suggest that the analysis of the metasentence that can be created to express the relation between a title/heading and the labeled text unit provides information about the heading's function. For instance, a heading like "Rare Metals" may be expressed with the discursive counterpart "This text unit is about rare metals". In contrast, a heading like "Section I" does not have as its discursive counterpart "This text unit is about section I" but rather "This text unit is the first section of the text". As another example, a more complex title like "An Essay on the Principle of Population" is a hybrid of the two types of 
examples above; it may be reformulated as a more complex metasentence that states its function and what it is about: "This text unit is an essay about the principle of population". Adopting the principle that a heading may be reformulated as a metasentence (because a heading is a realization of a metasentence) provides SARA with a means to describe titles and headings and, more generally, any signaling device. Based on this approach to understanding the purposes of signaling devices, SARA proposes that signals may be analyzed along four dimensions:

- a signal communicates one or more of seven specific types of information, which we refer to as the "information functions" of signals;

- a signal refers to a specific text object, thus it has a "scope";

- a signal is a particular combination of visual and/or discursive cues that we refer to as its "realization" in a text;

- a signal has a location with respect to the text object with which it is associated.

These dimensions of signals are useful both for analyzing existing signaling devices and for designing materials for empirical purposes. Moreover, as they have likely implications for text processing, they are used in the reader-based component in order to generate predictions concerning their potential effects on text processing.

\subsection{The reader-based component of SARA}

SARA proposes that a signal will influence text processing if the information that the signal makes available is both relevant to the reader's goals and easily accessible to cognitive processes. SARA's analysis of the information functions of signals addresses the question of what information is made available by a particular signaling device. The question of task relevance is an entirely reader-based consideration: If the information provided by a signal is relevant to the readers' goals then they will attend to the signals; otherwise, the signals will be ignored (Golding \& Fowler, 1992). Finally, when a signal makes available information that is relevant to the reader, the nature and extent of the signaling device's influence on processing will depend upon the accessibility to cognitive processing of the signaled information. Accessibility refers to the ease with which readers can use the information. It should depend upon the other three dimensions of signals: their realization properties, their scope, and their location with respect to the signaled text object. As an example, information about the organization of topics in a text is more accessible if it is communicated by an advance outline than if it is communicated by a system of headings interspersed in a text because the outline relieves the reader of gathering all the information together.

The initial consideration for understanding the effects of a signaling device on text processing is: what information does the signaling device make available? That is, what are the information functions of signals? SARA hypothesizes that any signaling device serves one or more of seven distinguishable information functions: 
- signals may demarcate underlying structural boundaries in a text;

- signals may label a part of a text;

- signals may identify the topic of a part of a text;

- signals may identify the function of a part of a text;

- signals may communicate the linear organization of sections of a text;

- signals may communicate the bierarcbical organization of text sections;

- signals may emphasize a part of a text.

In fact, headings typically communicate several types of information. Given our definition of headings, all headings demarcate text sections and provide a unique label for each section. In addition, all conventional uses of headings appear to involve emphasis of the heading (e.g. with unique typography and/or spatial separation from the body of the text). However, headings vary with respect to the other four information functions, as illustrated in Table I. Many headings are used to identify the topics of the sections they head. As we have already noted, however, not all headings are topic-identifying. Rather, headings are sometimes used to identify only the function of a section (e.g. to "introduce" or to "summarize"). It is possible to combine the two functions, too. Headings may explicitly communicate the sequential organization of the sections of a text; in fact, headings sometimes consist solely of numbers at the start of each new text section (e.g. chapters in a novel). Headings often use typographical and spatial contrast to communicate the hierarchical organization of text sections, or they may communicate such information more explicitly with lettering and/or numbering of text sections. These variations in headings lend themselves to different cognitive functions and can therefore be expected to influence text processing, as we will see in the next section of the text.

Assuming that the information communicated by a signaling device is relevant to a reader's goals, the dimensions of realization, scope and location can all be expected to influence text processing. It is possible to construct signaling devices that communicate the same information (i.e. serve the same information functions) but differ with respect to either how they are realized in a text, or their scope, or their location. For example, parallel versions of headings and preview sentences may be constructed. The preview sentence at the start of a new text section might be: "In this section, we will discuss the information functions of signaling devices" or the same information might be communicated by the heading "Information Functions of Signaling Devices". According to SARA, both the preview sentence and heading explicitly demarcate the structure boundary, provide a label for the section, and identify the topic of the section, and - in this example - both receive emphasis. However, the two signals are realized differently; whereas the preview sentence is completely explicit in its communication that a new section is beginning, the heading communicates this information implicitly by being set off spatially from the preceding and following sections. This visual communication of demarcation by 
the heading is a more visually salient cue that might result in more attention on the part of the reader. In other words, the difference in visual salience may make the information about the structural boundary more accessible to cognitive processing (Lorch, Chen \& Lemarié, in press).

\begin{tabular}{|c|c|c|c|c|c|}
\hline & Examples of headings & Topic & Function & Content & Hierarchical \\
\hline I & $\begin{array}{l}\text { Oil Spills } \\
\text { Air Pollution } \\
\text { Acid Rain }\end{array}$ & $\mathrm{X}$ & -- & -- & -- \\
\hline 2 & $\begin{array}{l}\text { Introduction } \\
\text { Discussion } \\
\text { Conclusion }\end{array}$ & -- & $\mathrm{X}$ & -- & -- \\
\hline 3 & $\begin{array}{l}\text { A. Introduction } \\
\text { B. Discussion } \\
\text { C. Conclusion }\end{array}$ & -- & $\mathrm{X}$ & $\mathrm{X}$ & -- \\
\hline 4 & $\begin{array}{l}\text { Section I } \\
\text { Section I.I } \\
\text { Section I.2 } \\
\text { Section I.2.I } \\
\text { Section I.2.2 } \\
\text { Section } 2\end{array}$ & -- & $\mathrm{X}$ & $\mathrm{X}$ & $\mathrm{X}$ \\
\hline 5 & $\begin{array}{l}\text { Chapter I: Oil Spills } \\
\text { Chapter 2: Air Pollution } \\
\text { Chapter 3: Acid Rain }\end{array}$ & $\mathrm{X}$ & $\mathrm{X}$ & $\mathrm{X}$ & -- \\
\hline 6 & $\begin{array}{l}\text { ENERGY PROBLEMS } \\
\text { Oil Spills } \\
\text { Air Pollution } \\
\text { Acid Rain }\end{array}$ & $\mathrm{X}$ & -- & -- & $\mathrm{X}$ \\
\hline 7 & $\begin{array}{l}\text { Section A: ENERGY PROBLEMS } \\
\text { Chapter I: Oil Spills } \\
\text { Chapter 2: Air Pollution } \\
\text { Chapter 3: Acid Rain }\end{array}$ & $\mathrm{X}$ & $\mathrm{X}$ & $\mathrm{X}$ & $\mathrm{X}$ \\
\hline
\end{tabular}

Table 1. An analysis of the information function of diverse headings

Consider another example comparing a set of headings to an advance outline that consists of the same labels as the headings. Both the advance outline and the headings provide the same topic-identifying labels for the text sections, but the headings provide the relevant label immediately preceding the relevant section whereas the advance outline provides the label generally far in advance of the relevant sections. This difference in the location of the labels with respect to their associated sections has implications for whether the relevant background knowledge will be accessed at the time a new section is encountered; the knowledge is likely to be activated by the 
headings at the appropriate time (Wiley \& Rayner, 2000) but may not be activated at the appropriate time by an advance outline. Conversely, as already mentioned, an advance outline makes information about the sequential and hierarchical organization of the text more accessible compared to a system of headings.

Finally, it is easy to imagine that a brief or a longer section of a text might be written, both with the same heading. The variation in the length of the text section corresponds to a difference in the scope of the heading. One implication of changing the scope of a signaling device is that its influence might be generally be decreased as the scope increases because its relation to any specific content is likely to become less direct and/or more ambiguous.

To summarize, SARA provides a formal definition of signals, in general, and headings, in particular, that serves to clearly define the domain. Further, SARA offers a systematic analysis of the dimensions on which signals, including headings, vary and it offers hypotheses about how such variation may influence cognitive processing. We hope that the theoretical framework makes it clear that it is important for researchers to characterize their manipulations of titles and headings with respect to all of these dimensions identified by SARA in order that the conclusions from future research may be theoretically more precise and more useful in applications.

\section{Implications of SARA's analysis of information functions for research on headings}

From a cognitive perspective, the most important implication of SARA's analysis of the information functions of headings is that different information functions are likely to have different effects on text processing. For example, a heading that identifies the topic of a text section provides the reader with potentially important contextual information for understanding the content of the subsection (Bransford \& Johnson, 1972; Ritchey, Schuster \& Allen, 2008; Surber \& Schroeder, 2007), whereas a heading that identifies the function of a text section may guide reading processes by activating knowledge about conventional categories of text content. Similarly, a heading that communicates organizational information may trigger processing of relations between two subsections that otherwise will not occur (Hyönä \& Lorch, 2004).

Until now, researchers generally have not distinguished different types of headings (Brooks et al., 1983; Hyönä \& Lorch, 2004; Krug et al., 1989; Lorch \& Lorch, 1996a; Lorch et al., 200I; Sanchez, Lorch \& Lorch, 200I). This means that researchers' interpretations of the effects of headings are often more specific than their manipulations support. For example, researchers have often attributed effects of headings to their influence on the processing of text organization. However, previous studies have typically compared a headings condition to a no headings control condition. Thus, when headings are shown to produce better recall, it is not possible to determine whether the benefits of headings are due to 
their communication of organizational information or to some other information function of the heading (e.g. demarcation, topic identification, labeling, or some combination of multiple types of information).

We recently reported a series of experiments designed to test the validity of SARA's analysis of signaling devices as communicating seven distinguishable types of information (Lorch, Lemarié \& Grant, zorıa and b). Prior evidence adequately demonstrates the validity of the information function of "emphasis" (Cashen \& Leicht, 1970; Crouse \& Idstein, 1972; Fowler \& Barker, 1974; Golding \& Fowler, 1992; Lorch, Lorch \& Klusewitz, 1995). The experiments to be summarized here tested the remaining six information functions. For each experiment, the logic was the same. Namely, each experiment set up a comparison designed to isolate a single information function under conditions where the hypothetical information was both highly relevant to task performance and easily accessible to the reader. For example, readers in one experiment were required to answer questions that targeted specific sentences within a text. They were timed to locate the specific sentences in texts that had topic-identifying headings or texts that had headings that did not identify topics. The two types of headings served the functions of demarcating and labeling text sections and providing information about the linear structure of the text; they differed only with respect to whether they identified topics. Because the questions were easy to relate to the topics of the text sections, the topic identifying information was highly relevant to the task. Not surprisingly, readers did use this information as demonstrated by the finding that search times were much faster in the topic-identifying condition than in the control condition (Lorch, Lemarié \& Grant, 2orrb). Thus, the validity of the information of topic identification is supported by this result.

The remaining five information functions also found support in our experiments. In another search experiment, readers located targeted sentences more rapidly if the questions they were answering provided the label for the relevant text section than if the questions did not provide the labels (Lorch, Lemarié \& Grant, 2orrb). This outcome supports distinguishing the information function of labeling from other functions.

Search performance was also faster when the questions specified sections that were numbered sequentially than the questions specified sections that were numbered with a hierarchical scheme. However, performance in an outlining task was better if a text used a hierarchical numbering scheme than if the text used a sequential numbering scheme (Lorch, Lemarié \& Grant, 20IIa). The findings support the distinction between sequential and hierarchical information functions of headings.

Providing very simple demarcating information (i.e. a row of asterisks) before a section of text has a clear influence on readers' identifications of important text content in a summarization task. Readers are much more likely to designate as important statements from paragraphs immediately following the demarcating information than to designate statements from other paragraphs. Further, this is 
the case even when the demarcating information is placed before paragraphs that are subordinate in the text structure (Lorch, Lemarié \& Grant, 20Irb). This result supports the information function of demarcation as distinguishable from other information functions of headings.

Finally, the information function of function identification receives support from two separate studies. First, Lorch and Lorch (1986) found that readers process a sentence more slowly if its function is explicitly labeled than if the function is not labeled. In addition, they remember the signaled content better. Second, a recent experiment in our lab (Chen \& Lorch, in preparation) required participants to read a long text in preparation to recall its main points. Participants were under time pressure to complete their reading so they needed to develop an efficient reading strategy. Both versions of the text had function identifying headings that sequentially numbered every section, but two of the headings were replaced by the functional heading "summary" in the experimental condition. Participants receiving this text recalled more content from the summary sections than participants receiving the control version of the text, demonstrating that participants in the experimental condition developed a reading strategy that utilized the relevant function-identifying heading, "summary".

To summarize, our research validates SARA's analysis of headings (and other signaling devices) as communicating several distinguishable types of information about text structure and content that have distinct implications for text processing.

\section{Other research implications of SARA: future directions}

The immediate implication of our research findings is that it is not meaningful to ask the question "how do headings influence text processing?". Rather, an understanding of the effects of headings (and other signaling devices) on text processing must be based on an analysis of the information functions served by the headings. Headings that demarcate and label text sections simply by numbering them can be expected to have very different effects on text processing than headings that demarcate, label and identify the topics of text sections. Thus, SARA changes the level of analysis from the heading to their information functions.

We have demonstrated that the information that a signal makes available is the starting point for understanding how signals like headings influence text processing. But SARA emphasizes that it is by no means the sole consideration in understanding signaling effects. Rather, SARA hypothesizes that the effects of a signaling device will be moderated both by the relevance of the signaled information to the reader and by the accessibility of the signaled information to cognitive processing. Thus, important questions for future research are to more thoroughly develop the constructs of relevance and accessibility and examine their influence on signaling effects.

Although SARA provides a foundation for a better understanding of how headings influence text processing, the theory does not provide a complete analysis 
of headings. More research is needed to interface the model with ongoing linguistic studies of the different realizations and functions of headings. SARA can indeed be seen as providing a framework for such an interface, situating headings in the broader perspective of a theory of text signals. The different information functions of headings according to SARA are congruent with the analysis based on Halliday's metafunctions (section 2), insofar as both hypotheses take into account three different processes taking place concurrently — text construction, reference, interaction-, along with the idea that headings are generally concerned with several of these processes. Other discourse models or empirical studies may provide inspiration for further research. We sketch below two possible lines of enquiry.

The first one is concerned with the elusive notion of topic, a particularly difficult construct in discourse linguistics. What does it mean to say that a title or heading serves to identify the topic of a text or text segment? Two approaches may be distinguished in the literature: in the first one, discourse topic is envisaged in terms of "major participants" (Givón, 1983), identifiable thanks to referential expressions (cf. "topical chains": Cornish, 1998) which recur from utterance to utterance, thus creating referential continuity and topical unity. In opposition to this participant-oriented view, Van Dijk (198I) insists on the theoretical difference between sentence (or utterance) topic and discourse topic, and suggests that the latter should be viewed not as a referent but as a (macro-) proposition summarizing the text's macro-structure. Rebeyrolle, Jacques and Péry-Woodley (2009) build on these two conceptions of discourse topic to interpret a distinction, initially based on empirical observation, between two types within what SARA calls topic-identifying headings. The first type, "referential headings", is characterized by the fact that the referent mentioned in the heading is immediately picked up in subsequent text, either via repetition of the initial referential expression or via an anaphoric expression. In this case the heading identifies the topic as major participant. In the second type, "topical headings", the heading presents a topic more akin to Van Dijk's discourse topic. This propositional topic can take the form of a verbal noun, nominalization, infinitive clause or even a clause with a finite verb, and there is no direct repetition in the text, but rather topical development making use of different - though thematically related- expressions. As the authors point out, these initial insights need to be investigated further, and may provide an interesting testing ground for associating psychological experiments and corpus study. From a cognitive perspective, this dimension is relevant to an analysis of the processing requirements of a text (Eyrolle, Virbel \& Lemarié, 2008). For example, if a heading provides a generalization that serves to integrate ideas in the following text, then the presence of the heading may greatly facilitate text processing. In the absence of such a heading, the reader must produce the generalization or comprehension will suffer. On the other hand, if the reader is successful in producing the appropriate generalization, the result might actually be better comprehension than if a heading relieved the reader of the necessity of making the generalization (McNamara et al., 1996). The investigation of the topic identification function associated to titles 
and headings could be supported by a technique such as Latent Semantic Analysis (e.g. Landauer, Foltz \& Laham, 1998) which provides indicators of semantic similarity between pieces of information.

A second potentially fruitful line of enquiry is suggested by the examples in Table I. In all cases, several headings are provided in order to situate in context the specific heading being analyzed, although at this stage the relations between headings are not analyzed. Looking more closely, it is clear that in each example the headings work together as a set, and that different kinds of relations apply between the members of the sets. As "Air Pollution" comes after "Oil Spills" in the first example, a list effect is created, which is then reinforced by the third heading, and induces the creation of a superordinate topic, expressed by "Energy Problems" in the last two examples. This list effect may be made more or less explicit in the wording of the heading: it is partly lost in the version with numbered chapters (example 5), whereas it is greatly reinforced when the superordinate topic is expressed in a title (example 6) or higher level heading (example 7). These list-like sets of headings work in a way which is clearly different from the purely sequential functional set in the fourth example ("Section I" etc.). These different relations between headings within a set are likely to have an impact on the ways in which individual headings affect cognitive processes, and are therefore worth studying.

In conclusion, an important challenge for SARA will be to further develop its analysis of the ways in which titles and headings relate to specific content within the text that they signal. One important idea developed in this article is that better descriptions of headings (and other signaling devices) will enrich educational and cognitive research and lead to a better understanding of how headings influence text processing. To reach this goal, we urge more collaboration between linguists, psycholinguists and cognitive psychologists. Such collaboration will have several benefits for research on text signaling. One benefit for psychologists is that linguistic analyses of text will lead to more precise characterizations of text and manipulations of text characteristics (e.g. signaling devices). Second, linguistic corpus studies aiming at identifying the variability of text signaling devices may help psychologists to select comparisons that nicely reflect how writers effectively use text signaling. In turn, the comparison between the results obtained by psychology research on the signaling effects and the findings from corpus studies may lead to writing recommendations that are more compatible with the actual use of signaling devices.

\section{References}

Austin, J.L. 1962. How to Do Things with Words: The William James Lectures Delivered at Harvard University in 1955. Oxford: Clarendon Press.

Bock, M. 1980. Some Effects of Titles on Building and Recalling Text Structures. Discourse Processes 3 (4): 30I-3II. 
Bransford, J.D. \& Johnson, M.K. 1972. Contextual Prerequisites for Understanding: Some Investigations of Comprehension and Recall. Journal of Verbal Learning and Verbal Behavior II (6): 717-726.

Brooks, L.W. et al. 1983. Effects of Headings on Text Processing. Journal of Educational Psychology 75 (2): 292-302.

Cashen, V.M. \& Leicht, K.L. I970. Role of the Isolation Effect in a Formal Educational Setting. Journal of Educational Psychology 6I (6): 484-486.

Cauchard, F. et al. 2oroa. Vertical Perceptual Span and the Processing of Visual Signals in Reading. International Journal of Psychology 45 (I): 40-47.

Cauchard, F. et al. 2orob. Visual Signals Vertically Extend the Perceptual Span in Searching a Text: A Gaze-Contingent Window Study. Discourse Processes 47 (8): 617-640.

Chen, H.-T. \& Lorch, R.F. Jr. manuscript in preparation. Using Summary Indicators to Improve Text Processing Efficiency.

Cornish, F. 1998. Les «chaînes topicales»: leur rôle dans la gestion et la structuration du discours. Cabiers de grammaire 23: 19-40.

Crouse, J.H. \& Idstein, P. 1972. Effects of Encoding Cues on Prose Learning. Journal of Educational Psychology 63 (4): 309-313.

Dooling, D.J. \& Lachman, R. I97I. Effects of Comprehension on Retention of Prose. Journal of Experimental Psychology 88 (2): 216-222.

Dooling, D.J. \& Mullet, R.L. 1973. Locus of Thematic Effects in Retention of Prose. Journal of Experimental Psychology 97 (3): 404-406.

Eyrolle, H., Virbel, J. \& Lemarié, J. 2008. Impact of Incomplete Correspondence between Document Titles and Texts on Users' Representations: A Cognitive and Linguistic Analysis Based on 25 Technical Documents. Applied Ergonomics 39 (2): 24I-246.

Fowler, R.L. \& BARKER, A.S. 1974. Effectiveness of Highlighting for Retention of Text Material. Journal of Applied Psychology 59 (3): 358-364.

Genette, G. 1987. Seuils. Poétique. Paris: Seuil.

Givón, T. 1983. Topic Continuity in Discourse. Amsterdam - Philadelphia: John Benjamins.

Golding, J.M. \& Fowler, S.B. 1992. The Limited Facilitative Effect of Typographical Signals. Contemporary Educational Psychology I7 (2): 99-II3.

Grice, H.P. 1957. Meaning. The Philosophical Review 66 (3): 377-388.

Halliday, M.A.K. 1985. An Introduction to Functional Grammar. London: Edward Arnold.

Harris, Z.S. 1968. Mathematical Structures of Language. New York: Interscience Publishers.

HARRIS, Z.S. I99I. A Theory of Language and Information: A Mathematical Approach. Oxford: Clarendon Press.

Hartley, J. \& Trueman, M. 1983. The Effects of Headings in Text on Recall, Search and Retrieval. British Journal of Educational Psychology 53 (2): 205-2I4.

Ho-Dac, L.-M., Jacques, M.-P. \& Rebeyrolle, J. 2004. Sur la fonction discursive des titres. In S. Porhiel \& D. Klinger (eds), L'unité texte. Pleyben: Perspectives: I25-152.

Holley, C.D. et al. 198I. Utilizing Intact and Embedded Headings as Processing Aids with Nonnarrative Texts. Contemporary Educational Psychology 6 (3): 227-236. 
HYöNÄ, J. \& LORCH, R.F. Jr. 2004. Effects of Topic Headings on Text Processing: Evidence from Adult Readers' Eye Fixation Patterns. Learning and Instruction I4 (2): I3I-I52.

JACQUes, M.-P. 2005. Structure matérielle et contenu sémantique du texte écrit. Corela 3 (2). Available online: http://corela.edel.univ-poitiers.fr/index.php?id= 560 .

Jacques, M.-P. \& Rebeyrolle, J. 2006. Titres et structuration des documents. Schedae, prépublication I, fascicule I: I-I2. Available online: http://www.unicaen.fr/services/puc/ ecrire/preprints/preprintooı20o6.pdf.

Kozminsky, E. 1977. Altering Comprehension: The Effect of Biasing Titles on Text Comprehension. Memory and Cognition 5 (4): 482-49o.

Krug, D. et al. 1989. The Effect of Outlines and Headings on Readers' Recall of Text. Contemporary Educational Psychology I4 (2): III-I23.

La HaYe, F. de et al. 2009. Les évaluations en lecture dans le cadre de la journée d'appel de préparation à la défense. Année 2009. Note d'information IO.II. MEN-DEPP.

Landauer, T.K., Foltz, P.W. \& Laham, D. 1998. An Introduction to Latent Semantic Analysis. Discourse Processes 25 (2-3): 259-284.

LemariÉ, J. et al. 2008. SARA: A Text-Based and Reader-Based Theory of Signaling. Educational Psychologist 43 (I): 27-48.

Lorch, R.F. Jr. 1989. Text-Signaling Devices and Their Effects on Reading and Memory Processes. Educational Psychology Review I (3): 209-234.

Lorch, R.F. Jr., Chen, H.-T. \& Lemarié, J. in press. Communicating Headings and Preview Sentences in Text and Speech. Journal of Experimental Psychology: Applied.

LorCH, R.F. Jr. et al. 2oor. Effects of Headings on Text Summarization. Contemporary Educational Psychology 26 (2): I7I-I9I.

Lorch, R.F. Jr., Lemarié, J. \& Grant, R.A. 2oira. Signaling Hierarchical and Sequential Organization in Expository Text. Scientific Studies of Reading I5 (3): 267-284.

Lorch, R.F. Jr., Lemarié, J. \& Grant, R.A. 2oirb. Three Information Functions of Headings: A Test of the SARA Theory of Signaling. Discourse Processes 48 (3): 139-I60.

Lorch, R.F. Jr. \& Lorch, E.P. 1985. Topic Structure Representation and Text Recall. Journal of Educational Psychology 77 (2): 137-I48.

Lorch, R.F. Jr. \& LorCH, E.P. 1986. On-Line Processing of Summary and Importance Signals in Reading. Discourse Processes 9 (4): 489-496.

LORCH, R.F. Jr. \& LORCH, E.P. 1995. Effects of Organizational Signals on Text-Processing Strategies. Journal of Educational Psychology 87 (4): 537-544.

LoRCH, R.F. Jr. \& LoRCH, E.P. 1996a. Effects of Headings on Text Recall and Summarization. Contemporary Educational Psychology 2I (3): 26I-278.

LorCH, R.F. Jr. \& LorCH, E.P. 1996b. Effects of Organizational Signals on Free Recall of Expository Text. Journal of Educational Psychology 88 (I): 38-48.

Lorch, R.F. Jr., Lorch, E.P. \& InMan, W.E. 1993. Effects of Signaling Topic Structure on Text Recall. Journal of Educational Psychology 85 (2): 28I-290.

Lorch, R.F. Jr., Lorch, E.P. \& KLusewitz, M.A. 1995. Effects of Typographical Cues on Reading and Recall of Text. Contemporary Educational Psychology 20 (I): 5I-64. 
Mautone, P.D. \& Mayer, R.E. 20or. Signaling as a Cognitive Guide in Multimedia Learning. Journal of Educational Psychology 93 (2): 377-389.

Mayer, R.E. 1978. Advance Organizers that Compensate for the Organization of Text. Journal of Educational Psychology 70 (6): 880-886.

Mayer, R.E., Dyck, J.L. \& Cook, L.K. 1984. Techniques that Help Readers Build Mental Models from Scientific Text: Definitions Pretraining and Signaling. Journal of Educational Psychology 76 (6): I089-IIO5.

McNamara, D.S. et al. 1996. Are Good Texts Always Better? Text Coherence, Background Knowledge, and Levels of Understanding in Learning from Text. Cognition and Instruction I4 (I): I-43.

MeYer, B.J.F. et al. I998. Interest and Strategies of Young and Old Readers Differentially Interact with Characteristics of Texts. Educational Gerontology 24 (8): 747-77I.

PASCUAL, E. I99I. Représentation de l'architecture textuelle et génération de texte. Unpublished $\mathrm{PhD}$ thesis. Université Paul Sabatier. Toulouse.

Rebeyrolle, J., Jacques, M.-P. \& Péry-Woodley, M.-P. 2009. Titres et intertitres dans l'organisation du discours. Journal of French Language Studies 19 (2): 269-290.

Ritchey, K., Schuster, J. \& Allen, J. 2008. How the Relationship between Text and Headings Influences Readers' Memory. Contemporary Educational Psychology 33 (4): $859-874$.

SAnchez, R.P., Lorch, E.P. \& LoRch, R.F. Jr. 200I. Effects of Headings on Text Processing Strategies. Contemporary Educational Psychology 26 (3): 418-428.

SCHALleRT, D.L. 1976. Improving Memory for Prose: The Relationship between Depth of Processing and Context. Journal of Verbal Learning and Verbal Bebavior I5 (6): 62I-632.

Schwarz, M.N.K. \& Flammer, A. 198I. Text Structure and Title-Effects on Comprehension and Recall. Journal of Verbal Learning and Verbal Bebavior 20 (I): 6I-66.

SEARLE, J.R. 1969. Speech Acts: An Essay in the Philosophy of Language. Cambridge: Cambridge University Press.

SEARLE, J.R. 1979. Expression and Meaning: Studies in the Theory of Speech Acts. Cambridge New York: Cambridge University Press.

Smith, E.E. \& Swinney, D. I992. The Role of Schemas in Reading Text: A Real-Time Examination. Discourse Processes i5 (3): 303-316.

SpyridAKIs, J.H. 1989. Signaling Effects: A Review of the Research. Journal of Technical Writing and Communication I9 (3): 227-240.

Spyridakis, J.H. \& Standal, T.C. 1986. Headings, Previews, Logical Connectives: Effects on Reading Comprehension. Journal of Technical Writing and Communication I6 (4): 343-354.

Spyridakis, J.H. \& Standal, T.C. 1987. Signals in Expository Prose: Effects on Reading Comprehension. Reading Research Quarterly 22 (3): 285-298.

Sulin, R.A. \& Dooling, D.J. 1974. Intrusion of a Thematic Idea in Retention of Prose. Journal of Experimental Psychology IO3 (2): 255-262.

Surber, J.R. \& Schroeder, M. 2007. Effect of Prior Domain Knowledge and Headings on Processing of Informative Text. Contemporary Educational Psychology 32 (3): 485-498. 
Van Dijk, T.A. 198I. Studies in the Pragmatics of Discourse. The Hague - Paris - New York: Mouton.

VIrbeL, J. 1985. Langage et métalangage dans le texte du point de vue de l'édition en informatique textuelle. Cabiers de grammaire IO: 5-72.

Virbel, J. 1989. The Contribution of Linguistic Knowledge to the Interpretation of Text Structures. In J. André, V. Quint \& R. Furuta (eds), Structured Document. Cambridge: Cambridge University Press: I8I-I90.

VIRBEL, J. 2002. Éléments de description du titre. In Actes du colloque "Inscription spatiale $d u$ langage: structure et processus» (ISLsp-29-30 janvier 2002, Toulouse). Toulouse: IRIT: $123^{-1} 34$.

VIRBEL, J. 2005. Les objets textuels de type titre. In Actes du séminaire REHSEIS/IRIT "Histoire des sciences, histoire du texte» (I2 mai 2005).

VIRBEL, J. 2008. À propos des métaphrases sources des titres «thématiques». Unpublished manuscript.

Waller, R.H.W. 1987. The Typographic Contribution to Language: Towards a Model of Typographic Genres and Their Underlying Structures. Unpublished PhD thesis. University of Reading, Department of Typography and Graphic Communication.

Wiley, J. \& RAYNER, K. 20oo. Effects of Titles on the Processing of Text and Lexically Ambiguous Words: Evidence from Eye Movements. Memory and Cognition 28 (6): IOII-IO2I. 